\title{
EM BUSCA DE UMA EDUCAÇÃO FÍSICA ESCOLAR ALTERNATIVA
}

\author{
Luiz Alberto LORENZETTO*
}

Tenho encontrado em alguns manuais as funções da Educação Física Escolar apresentadas sob as mais variadas formas.

Algumas destas funções estão reunidas através de objetivos que eu chamaria de específicos e "tradicionais", como por exemplo, propiciar aos alunos, a possibilidade de:

1. aprender e aperfeiçoar suas habilidades motoras;

2. desenvolver suas capacidades físicas;

3. aumentar o seu círculo de amizades;

4. encontrar seu equilibrio afetivo-emocional;

5. aprender esportes, danças e jogos;

6. preparar-se para uma competição ou apresentação públicas, de nível intermunicipal ou interestadual.

Outros manuais apresentam seus objetivos de uma forma mais geral, não perdendo porém seu caráter "tradicional", como por exemplo:

1. despertar o aluno para a competição;

2. trabalhar o espírito de liderança do aluno;

3. desenvolver o "espírito esportivo" do aluno;

4. instrumentalizar o aluno para a aprendizagem de outras disciplinas;

5. desenvolver a criatividade do aluno;

6. adaptar o aluno às condições sociais.

Embora eu discorde de alguns e concorde com outros, reconheço como um grande problema educacional, o fato destes objetivos, na quase totalidade das vezes, virem desacompanhados dos valores que os geraram. Assemelham-se a um barco que, não sabendo de onde saiu, não sabe onde aportar.

Sônia Aparecida Ignácio Silva (1986), preocupada também com o fato acima, lamenta a falta, ainda que provisoriamente, de conhecimento e convicções percebidas nas decisões de alguns docentes, deixando sem consistência as necessárias interações existentes no ambiente escolar, o que pode ocasionar sérias contradições curriculares e comprometer a ação educativa.

A fim de não incorrer na fala que registrei (descrever os objetivos sem a devida fundamentação), antes de apresentar uma proposta referir-me-ei a alguns aspectos que considero importantes e que, por uma questão de coerência, estão definitivamente ligados aos meus próprios projetos de vida.

Em função da natureza deste estudo não pretendo esgotar o assunto (e nem sou capaz disso), e sim enumerar alguns aspectos através dos quais tenho procurado harmonizar educação, saúde, lazer, motricidade humana e atingir uma educação física escolar alternativa.

São eles:

1. ponto de partida;

2. motricidade e linguagem;

3. ausências e presenças;

*Departamento de Educação Física da Universidade Estadual Paulista - Rio Claro

Rev. paul. Educ. Fís., São Paulo, 5(1/2):45-50, jan./dez.1991. 
4. elementos constitutivos da motricidade;

5. em busca de uma Educação Física Escolar Alternativa.

6. e para completar...

\section{PONTOS DE PARTIDA}

Determinar o papel e o perfil do professor que trabalha com esportes, jogos, ginástica e dança é um bom ponto de partida, e a este respeito sugiro que ele deva:

- conhecer seu corpo e gostar dele

- conhecer os alunos e gostar deles

- conhecer a motricidade humana e gostar dela

- conhecer o processo ensino-aprendizagem e gostar dele

A estas quatro competências acrescento algumas características do professor, indispensáveis ao seu perfil: confiança, consciência. empatia, coragem, alegria, autenticidade e determinação.

Sendo uma pessoa que precisa enxergar mais longe que os mortais comuns, cabe-lhes muitas vezes a responsabilidade da decisão, como propõe o poeta Guillaume Apolinaire (citado por Marylin Ferguson, 1988).

"Cheguem até a borda, disse ele.

Eles responderam: temos medo.

Cheguem até a borda, ele repetiu.

Eles chegaram.

Ele os empurrou ...

Eles voaram."

Fazendo uma comparação com a atitude de um professor, é preciso que ele saiba:

- quando empurrar;

- que, com amor é mais fácil empurrar;

- e se, além de empurrar, ele deve voar junto com os alunos.

Pensando desta forma, três outras questões clarearão suas idéias, nortearão sua conduta e ele perguntar-se-á:

- o que estou oferecendo aos meus alunos?

- o que os meus alunos farão com aquilo que eu lhes estou oferecendo?

- como os meus alunos avaliarão as minhas ofertas?

Um professor preocupado com estes detalhes, certamente vai basear-se em princípios pedagógicos que atentem para a natureza, a individualidade e a expressividade dos alunos, respeitando sobremaneira o seu já adquirido acervo natural, resgatando e valorizando a memória das suas tradiçōes e do seu folclore.

\section{MOTRICIDADE E LINGUAGEM}

Se o corpo é a expressão da personalidade humana, ele precisa de vários recursos para comunicar-se e a sua motricidade está ligada aos mesmos aspectos que publicaracterizam a linguagem, como por exemplo:

- o significado

- a polissemia

a transcendência

- a estrutura

- a dialética 
- a metamorfose

- a transicionalidade

A motricidade humana deve ser significativa, isto $\varepsilon$, deve ter sentido. A prática pura e simples das habilidades motoras pode alienar o atleta, o ginasta, o dançarino, o nadador, fazendo com que o mesmo perca a sua dimensão humana. $O$ sentido da práxis (prática refletida) deve conduzí-lo (apenas para citar um exemplo) a harmonizar a força e a sensibilidade, porque uma sem a outra traz a desumanização. A força sem sensibilidade é truculência, cria prepotência e dela fazem uso os que não têm argumentos. A sensibilidade sem força é fraqueza, conduz à apatia e dela fazem uso os que não têm iniciativa e determinação. Outros sentidos a serem, alcançados: o lúdico, a estética, a justiça, o compartilhamento, a imaginação, etc.

A motricidade humana deve ser polissêmica, isto é, deve ter sentidos. A práxis deve permitir que cada aluno expresse a sua audácia, esforço, medo, calma, segurança, ansiedade, do seu jeito proprio e inimitável.

A motricidade humana deve ser transcendente, isto $\epsilon$, deve ter mais sentido. A práxis aliada à meditação deve conduzir o ser humano em busca de si proprio, em busca do outro, em busca de si próprio no outro, e em busca de todos num ideal comum e numa universalização do corpo.

A motricidade humana deve ser estrutural, isto $\dot{\epsilon}$, deve fazer com que todas as pessoas convivam com todos esses sentidos holisticamente. A práxis deve permitir a utilização intencional dos três domínios do comportamento: físico, afetivo e intelectual.

A motricidade humana deve ser dialética, isto $\epsilon$, deve remeter um sentido ao outro e torná-los reversíveis. A práxis deve permitir que os sentidos convivam entre si, mesmo quando eles pareçam ambíguos e conflitantes: a nobreza com a necessidade do sucesso, a vaidade com o altruísmo, etc.

A motricidade humana deve ser metamórfica, isto $\epsilon$, deve permitir a transformação dos sentidos. A práxis deve permitir o nascimento de um novo corpo, de uma nova corporeidade e de uma nova educação física escolar, transitando entre o real, o simbólico e o imaginário.

A motricidade humana deve ser transicional, isto é, deve estabelecer um vai-vem entre a fusionalidade (estado de dependência) e a autonomia (estado de independência) docente/discente. A práxis transicional implica a utilização do brinquedo, do jogo, do esporte, da dança, como ações ou objetos lúdicos, desenvolvidos entre o aluno e o professor, com a função não apenas de uni-los, mas também de preparar a sua separação.

A conquista de uma linguagem clara e precisa e de uma motricidade bem desenvolvida, significa não só o vislumbrante e a compreensão de novas significações, mas também a conquista de novas relações técnicas, espaciais e temporais.

A idéia de unir motricidade e linguagem através dos seis primeiros itens deste tópico, partiu de uma aula do Prof. Antônio Muniz de Rezende (1985, Faculdade de Educação da Unicamp), onde ele estabeleceu uma relação entre o símbolo e a linguagem.

A idéia do último item (transicionalidade) partiu da leitura de um livro de David W. Winnicot (1975).

\section{AUSÊNCIAS E PRESENÇAS}

A fim de garantir uma Educação Física Escolar alternativa e de criar um clima de aprendizagem onde o conflito possa conviver com a harmonia, o consenso com o dissenso, as semelhanças com as diferenças Eugênia Tereza de Andrade e Luiz Alberto Lorenzetto (citados por Lorenzetto, 1991, p.45-46-51-52-53) propõem o reconhecimento de algumas ausências e algumas presenças.

"A ausência de competições neuróticas e egoístas, que geram adversários (jogam contra tudo e contra todos em vez de concorrentes (jogam e compartilham)". 
"A presença do lúdico, que transforma, seduz, erotiza, abre as portas do sorriso, deixa no ar um cheiro de mistério, de surpresa e de 'sã loucura".

"A ausência de comparações, que igualam os diferentes e diferenciam os semelhantes".

"A presença do estético, que reforma a forma, molda a luz, colore a pipa e põe beleza no nada".

"A ausência de modelos muito rígidos, que legitimam o mesmo, defendem o igual e reproduzem o sempre".

"A presença da intuição, lógica do fantástico, chave da descoberta".

"A ausência da censura que trava corrompe, inutiliza, silencia, silen ..., sil ..."

"A presença da arte, que sensibiliza, molha os olhos, aperta e abre o coração."

"A ausência do conceito de corpo feio ou bonito, quando o que importa é que ele seja feliz."

E finalmente,

"A presença do sublime, onde o professor humaniza-se no aluno, o aluno humaniza-se no professor e ambos humanizam-se no fazer, no saber e no sabor".

\section{ELEMENTOS CONSTITUTIVOS DA MOTRICIDADE HUMANA}

Após refletir sobre algumas decisões, alguns valores, e algumas ações que caracterizam o ser humano, apresento uma tentativa de integração dos elementos constitutivos da motricidade, que representam, de forma resumida, uma maneira de instrumentalizar a ação docente/discente, atingir uma Educação Física Escolar Alternativa e permitir ao aluno: crescer, desenvolver-se, interagir e realizar-se.

Isto vai ser feito respondendo as perguntas que se seguem:

1. Quem se movimenta?

R. $O$ indivíduo na sua pluralidade, através:

a) da energia, que o move;

b) da informação, que o orienta;

c) da motivação, que o estimula.

2. Como ele se movimenta?

R. Através das relaçōes entre o espaço, o tempo, o peso, a fluência, os objetos e as pessoas.

3. Por que ele se movimenta?

R. Para aprender habilidades motoras, desenvolver capacidades físicas e aperfeiçoar técnicas de movimento, acompanhamento de todo o contexto biológico, psicológico e social que o influencia.

4. Quais os critérios dessa movimentação?

R. Que o aluno se movimente com naturalidade, segurança, graça, fluidez, precisão, dinamismo e harmonia.

Esquematicamente teremos: Elementos da motricidade humana

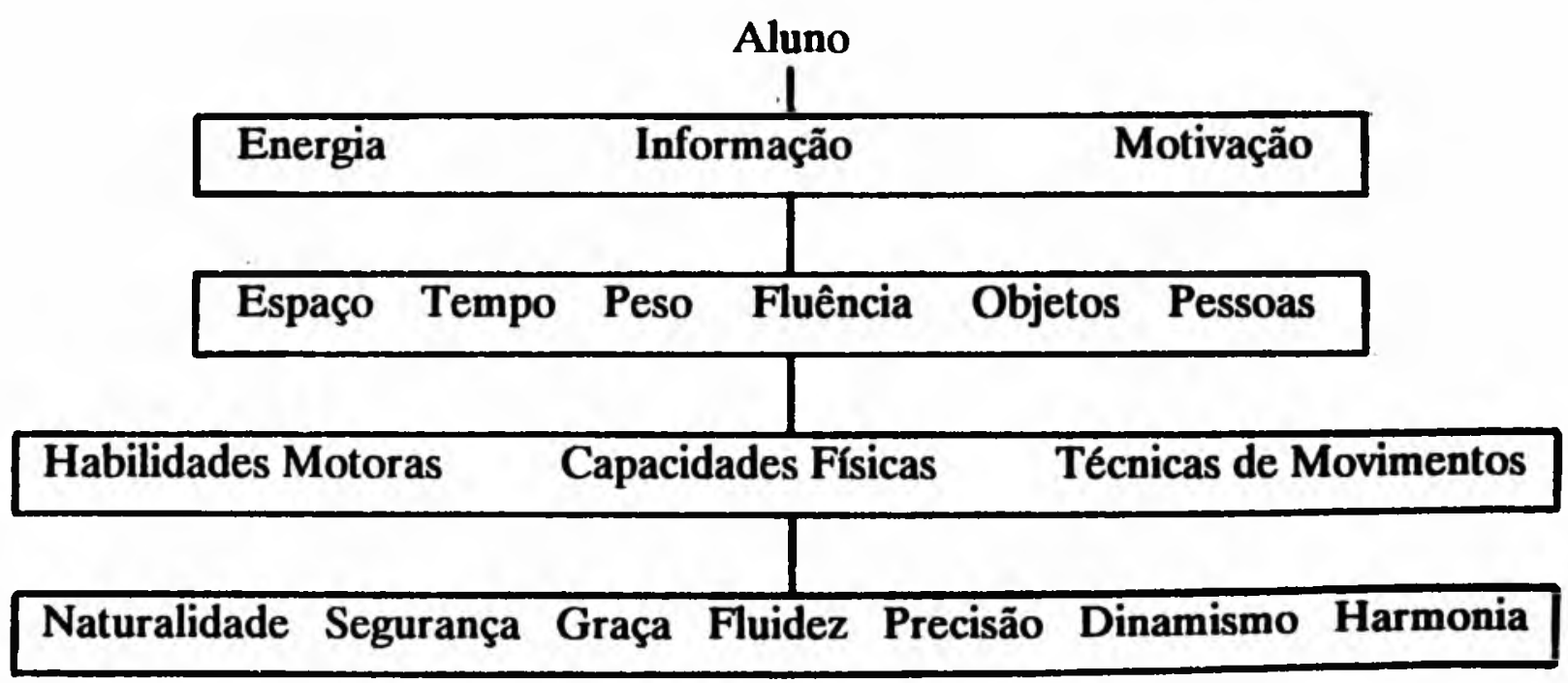




\section{EM BUSCA DE UMA EDUCAÇÃO FISICA ESCOLAR ALTERNATIVA}

Finalmente relaciono algumas funções (ou metas), para nortear a busca de uma Educação Física Escolar Alternativa, e tentar tornar mais clara a sua compreensão.

Não é presunção minha chamar esta resumida proposta de Alternativa, por considerá-la absolutamente diferente de outras tentativas de sistematização, mas por considerá-la uma proposta aberta, por ter contado com sugestões dos próprios alunos e por permitir a transcendência dos indivíduos nela engajados.

Portanto, após cumprir um programa que contenha todos os elementos constitutivos de motricidade, acredito que ao final da 3a. série do 20.grau, o aluno poderá estar apto para cumprir as funções propostas a seguir:

1. Selecionar atividades que melhor atendam suas necessidades, expectativas e desejos. Enquanto nos modelos tradicionais a Educação Física Escolar deve propiciar-lhe tais e tais funções, aqui

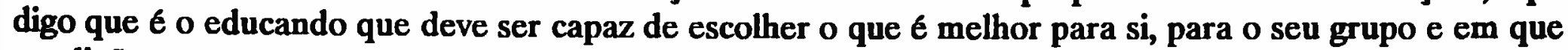
condições; comunicação;

2. Resolver criativamente problemas de movimento que envolvam vitalidade, emotividade e

3. Compreender sua bioenergia, desenvolver um tônus muscular mais equilibrado e harmonioso, relaxar, e restaurar a sensibilidade de todo o corpo através da Eutonia que em grego significa: Eu: harmonioso, belo; e tonia: tônus muscular. Portanto, equilíbrio do tônus muscular, uma técnica e trabalho segundo a professora Gerda Alexander (1983) da Dinamarca;

4. Movimentar-se com autenticidade, confiança, empatia, iniciativa, espontaneidade e prazer;

5. Através da consciência corporal, eliminar distúrbios do sono, da alimentação, da excreção, da postura e da imagem corporal;

6. Eliminar ou conviver com os efeitos do stress deteriorante, libertando-se das pressões intrínsecas e extrínsecas;

7. Experimentar mudanças de estado de consciência, através de um processo de reflexão, crítica e criação, que elimine as influências negativas da nossa existência partindo da perplexidade, o espanto diante das coisas, dos objetos, dos fatos e dos fenômenos, atingir a reflexão, dobrar-se em suas coisas, analisar o real, o imaginário e o simbólico, criticar e comprometer-se com aquilo que está fazendo, através daquilo que está sentindo, falando, investigando e, finalmente, criar. Não adianta nada criticarmos sem apresentarmos sugestões;

8. Encontrar sua unidade existencial dentro da pluralidade pessoal (holismo). Quer dizer, embora o ser humano seja ação, pensamento e emoção essas coisas acontecem conjuntamente; turmas mistas;

9. Atuar co-educacionalmente, reunindo e separando força e sensibilidade, num trabalho com

10. Recusar qualquer forma de opressão, exploração e sofrimento e valorizar todas as formas de justiça, beleza e generosidade;

11. Representar, expressar-se, transformar, transformar-se e transcender em todas as dimensões do real, do imaginário e do simbólico. Ir além do próprio corpo;

12. Desenvolver uma qualidade de movimento que atinja os seguintes níveis: naturalidade, segurança, dinamismo, fluidez, graça, precisão, harmonia.

\section{E PARA COMPLETAR ...}

Este texto não foi escrito apenas para ser lido, e sim para ser discutido. Por essa razão o autor gostaria de trocar idéias (por carta ou pessoalmente) através da UNESP Rio Claro (0195 340244).

Rev. paul. Educ. Fts., São Paulo, 5(1/2):45-50, jan./dez.1991. 
Um texto revestido de tantos aspectos filosoficos, entre os quais eu destaco dois: o ludico e o estético, só poderia terminar homenageando dois notáveis autores, que lhes dedicaram uma boa parte das suas obras, e que devem fundamentar qualquer decisão sobre a busca de uma Educação Fisica Escolar Alternativa.

"Gostaria de acreditar que a Educação Física está em paz com o corpo, que ela não deseja transformá-lo em puro meio para fins olímpicos (por pequenos que sejam), mas que tratasse de cuidar dele como coisa bela que deseja reaprender a esquecida arte de brincar (e de ser feliz)..." Rubem Alves (citado por Bruhns, 1989, p.42).

Não errará jamais quem buscar o ideal de beleza de um homem pela mesma via em que ele satisfaz seu impulso lúdico. A razão afirma que o homem deve somente jogar com a beleza, e somente com a beleza deve jogar. Pois, para dizer tudo de vez, o homem joga somente quando é homem no pleno sentido da palavra, e somente é homem pleno quando joga. Friedrich Schiller, 1989, p. 84.

\section{REFERÉNCIAS BIBLIOGRÁFICAS}

ALEXANDER, G. Eutonia: um caminho para a percepção corporal. São Paulo, Martins Fontes, 1983.

BRUHNS, H.T., org. Conversando sobre o corpo. Campinas, Papirus, 1989.

FERGUSON, M. Conspiração aquariana: transformações pessoais e sociais nos anos 80 . Rio de Janeiro, Record, 1988.

LORENZETTO, L. A. O corpo que joga o jogo do corpo. Campinas, 1991. Tese ( Doutorado) - Faculdade de Educação, Universidade Estadual de Campinas.

REZENDE, A. M. Notas de aulas. Faculdade de Educação da UNICAMP, Campinas, 1985.

SILVA, S.A.I. Valores em educação: o problema da compreensão e da operacionalização dos valores na prática educativa. Petrópolis, Vozes, 1986.

SCHILLER, F. A educação estética do homem. São Paulo, Iluminuras, 1989.

WINNICOT, D.W. O brincar e a realidade. Rio de Janeiro, Imago, 1975. 